\title{
Does the intramuscular tendon act like a free tendon?
}

\author{
Peter Brukner, ${ }^{1}$ jill L Cook, ${ }^{1}$ Craig Robert Purdam ${ }^{2}$
}

There has been an upsurge of interest, and some confusion, about the role of the connective tissue condensations within the lower limb muscles, notably biceps femoris, rectus femoris, gastrocnemius and soleus. These bands are variably referred to in the literature as intramuscular tendon, connective tissue, central tendon or aponeurosis, and can have a variable appearance (aponeurotic, cordlike) and vary between individuals. ${ }^{1}$

These intramuscular tendons (IMTs) act as central supporting struts to which the muscle fibres attach, and they smooth and amalgamate asynchronous motor unit contribution. Muscle strain may tear the myofibrillar attachments from the intramuscular tendon, with resultant bleeding and oedema. Occasionally, the damage may also involve a partial or complete tear of the intramuscular tendon itself.

When the intramuscular tendon is damaged, the injury is regarded as a more severe strain. Damage to the intramuscular tendon of the hamstring group has been associated with a prolonged return to play, ${ }^{2} 3$ although van der Made et $a l^{4}$ reported only a modest increase in return to play duration. Differences in the sporting demands of these cohorts may contribute to the discrepancy. Prolonged return to play has also been reported in intramuscular tendon injuries to the rectus femoris, gastrocnemius and soleus muscles. ${ }^{5}$

Specialised management (surgery, injection therapies, delayed rehabilitation) of an intramuscular tendon tear beyond standard muscle strain management has been proposed because of perceived failure to heal intramuscular tendon due to its tissue properties. Despite the similarities in collagenous structure in free tendon and intramuscular tendon, there are several reasons why injury to the intramuscular tendon may not be analogous to free tendon.

'La Trobe Sport and Exercise Medicine Research Centre, La Trobe University, Bundoora, Victoria, Australia ${ }^{2}$ Physical Therapies, Australian Institute of Sport, Bruce, Australia

Correspondence to Dr Peter Brukner, La Trobe Sport and Exercise Research Centre, La Trobe University, Melbourne, VIC 3086, Australia; peterbrukner@gmail. com

\section{HOW DO FREE TENDON AND INTRAMUSCULAR TENDON DIFFER IN STRUCTURE, FUNCTION AND PATHOLOGY?}

Structurally, the cross-sectional area of the isolated intramuscular tendon is substantially smaller than the free tendon it contributes to. At a histological level, it is unlikely to have the well-aligned fascicular bundles and the specialised interfascicular matrix seen in free tendon. The intramuscular tendon is composed primarily of type 1 collagen, organisationally more reticular at the endomyseal, perimyseal and epimyseal levels as it accumulates muscle forces from varying angles of pennation. ${ }^{6}$

Functionally, the free tendon can tolerate high strain rates to store and release energy. Resultant strains of up to $8 \%-10 \%$ are mostly derived from movement between the fascicle bundles in the interfascicular matrix, rather than of tendon collagen fibres themselves ${ }^{7}$. In contrast, the intramuscular tendon in an activated musculo-tendinous unit is considerably stiffer, with strains of $2 \%-2.6 \%{ }^{6}$ reported for triceps surae. Further, there is reported variability in longitudinal strain (some areas may shorten) and lateral expansion of up to $5 \%$; considered a result of oblique tension from pennate contributing fibrils as well as expansion of the whole muscle as it shortens. ${ }^{6}$ These properties may exist within other muscle groups. Ultimately, the lack of fascicular bundles and interfascicular matrix result in a functionally stiffer intramuscular tendon, which cannot store and release energy like free tendon.

Pathologically, free tendon succumbs to an overuse tendon pathology, eventually becoming degenerative in nature with little capacity to repair as there is little or no bleeding. Over time, the collateral regions of the tendon appear to remodel and increase tendon diameter to share load. ${ }^{8}$ Rarely, ruptures occur in the degenerative region, where an inflammation, proliferation and maturation response is triggered, resulting in a new matrix and considerably larger free tendon.

It is unlikely that intramuscular tendons have an overuse pathology and a pre-existing degenerative pathology as they have a higher vascular perfusion than free tendon. However, unlike the satellite cell response of myotendinous repair and similar to rupture in free tendon, intramuscular tendon ruptures result in bleeding and an inflammation, proliferation and maturation response, resulting in formation of hypertrophic intramuscular tendon scar tissue. Retraction of the stumps of intramuscular tendon lesions is generally limited as the surrounding muscle acts as a splint, which differs in free tendon ruptures. As such, surgery is rarely indicated.

Pain, generally localised at the tendon bone junction, is the presenting clinical feature of free tendon injury; this differs somewhat from recurrent structural failure and variable pain in IMT injury. While the sensory nerve supply of free tendons principally resides in the peritendon supplying the periphery of the tendon only, very little is understood about the neural supply of the intramuscular tendon; in particular, those Iintramuscular tendons that are deep within a muscle, as opposed to the more superficial aponeuroses. Clinically, particularly in intramuscular tendon strains of soleus and hamstring, presenting symptoms may be of progressive tightness or acute pain, which further clouds clinical assessment and prognoses.

This editorial highlights why intramuscular tendon does not behave like a free tendon either functionally or when injured. While many of the exercise progressions may be similar, there are symptomatic, structural and mechanical differences that should influence early and late phase rehabilitation principles. Perhaps the most appropriate term for the pathology should not include 'tendon' as it misleads our understanding of both the pathology and its management. 'Intramuscular aponeurosis' or 'intramuscular connective tissue' are appropriate terms that reflect the unique structural, behavioural and pathological properties.

Contributors All three authors have contributed equally to the writing of this editorial.

Funding The authors have not declared a specific grant for this research from any funding agency in the public, commercial or not-for-profit sectors.

Competing interests None declared.

Patient consent Not required.

Provenance and peer review Not commissioned; externally peer reviewed.

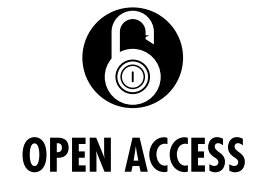

Open access This is an open access article distributed in accordance with the Creative Commons Attribution Non Commercial (CC BY-NC 4.0) license, which permits 


\section{Editorial}

others to distribute, remix, adapt, build upon this work non-commercially, and license their derivative works on different terms, provided the original work is properly cited, appropriate credit is given, any changes made indicated, and the use is non-commercial. See:@http:// creativecommons.org/licenses/by-nc/4.0/.

(c) Article author(s) (or their employer(s) unless otherwise stated in the text of the article) 2018. All rights reserved. No commercial use is permitted unless otherwise expressly granted.

\section{D) Check for updates}

To cite Brukner P, Cook JL, Purdam CR. Br J Sports Med 2018;52:1227-1228.

Accepted 22 May 2018

Published Online First 27 June 2018
Br J Sports Med 2018;52:1227-1228.

doi:10.1136/bjsports-2017-098834

\section{REFERENCES}

1 Brukner P, Connell D. 'Serious thigh muscle strains': beware the intramuscular tendon which plays an important role in difficult hamstring and quadriceps muscle strains. Br J Sports Med 2016;50:205-8.

2 Comin J, Malliaras P, Baquie P, et al. Return to competitive play after hamstring injuries involving disruption of the central tendon. Am J Sports Med 2013:41:111-5.

3 Pollock N, Patel A, Chakraverty J, et al. Time to return to full training is delayed and recurrence rate is higher in intratendinous (' $c$ ') acute hamstring injury in elite track and field athletes: clinical application of the British Athletics Muscle Injury Classification. Br I Sports Med 2016:50:305-10.
4 van der Made AD, Almusa E, Whiteley R, et al. Intramuscular tendon involvement on MRI has limited value for predicting time to return to play following acute hamstring injury. Br J Sports Med 2018;52.

5 Prakash A, Entwisle T, Schneider M, et al. Connective tissue injury in calf muscle tears and return to play: MRI correlation. Br J Sports Med 2017:bjsp orts-2017-098362.

6 Farris DJ, Trewartha G, McGuigan MP, et al. Differential strain patterns of the human Achilles tendon determined in vivo with freehand three-dimensional ultrasound imaging. J Exp Biol 2013;216(Pt 4):594-600.

7 Screen HRC, Bader DL, Lee DA, et al. Local strain measurement within tendon. Strain 2004;40:157-63.

8 Docking SI, Cook J. Pathological tendons maintain sufficient aligned fibrillar structure on ultrasound tissue characterization (UTC). Scand I Med Sci Sports 2016;26:675-83. 